\title{
Fast multiplex real-time PCR assay for simultaneous detection of dog and human blood and Leishmania parasites in sand flies
}

\author{
Kamila Gaudêncio da Silva Sales ${ }^{1}$, Débora Elienai de Oliveira Miranda ${ }^{1}$, Marcelo Henrique Santos Paiva ${ }^{2,3}$, \\ Luciana Aguiar Figueredo ${ }^{1}$, Domenico Otranto ${ }^{4,5}$ and Filipe Dantas-Torres ${ }^{1 *}$ (D)
}

\begin{abstract}
Background: The blood-feeding behaviour of female sand flies may increase their likelihood of acquiring and transmitting Leishmania parasites. Studies on the host usage by these insects may thus improve our understanding of the Leishmania transmission risk in leishmaniasis-endemic areas. Here, we developed a fast multiplex real-time PCR assay for simultaneous detection of dog, human and Leishmania DNA in sand flies.

Methods: Primers and TaqMan probes targeting the mitochondrial cytochrome c oxidase subunit 1 and cytochrome $b$ genes of dog and human, respectively, were combined in a multiplex assay, which also includes primers and a TaqMan probe targeting the Leishmania minicircle kinetoplast DNA.

Results: The multiplex assay was $100 \%$ specific, with analytical sensitivities of $10^{3} \mathrm{fg} /$ reaction for dog and human and $1 \mathrm{fg}$ for Leishmania. By testing field-collected engorged female sand flies (95 Migonemyia migonei and two Nyssomyia intermedia), $50 \mathrm{M}$. migonei were positive for one or two targets (positivity rates: $45.4 \%$ for human, $4.1 \%$ for dog and 12.4\% for Leishmania DNA).

Conclusions: This multiplex real-time PCR assay represents a novel fast assay for detecting dog, human and Leishmania DNA in female sand flies and therefore a tool for assessing the risk of Leishmania transmission to these hosts in areas of active transmission.
\end{abstract}

Keywords: Phlebotomine sand flies, Blood meal, Brazil, Real-time PCR

\section{Background}

Sand flies (Psychodidae: Phlebotominae) are insects of paramount medical and veterinary significance, mainly due to their competence in transmitting pathogens to many animal species, including humans [1]. Plant-derived carbohydrates (e.g. nectar, honeydew and phloem sap) are part of the diet of both male and female sand flies, being an essential source of energy for various activities, including flight and reproduction [2]. However,

*Correspondence: filipe.dantas@cpqam.fiocruz.br

1 Department of Immunology, Aggeu Magalhães Institute, Oswaldo Cruz Foundation (Fiocruz), Recife, Brazil

Full list of author information is available at the end of the article adult females are also blood-feeders and require vertebrate blood as a source of protein for oogenesis [3]. Thus, the feeding behaviour of female sand flies may influence their likelihood of acquiring and transmitting pathogens, including Leishmania parasites (Kinetoplastida: Trypanosomatidae), the causative agents of leishmaniases. To date, over 1000 sand fly species have been identified globally, of which more than $50 \%$ are exclusively found in the Neotropics [4]. About 98 species of sand flies have been listed as proven or suspected vectors of Leishmania spp. [1].

Leishmaniases are among the top ten neglected tropical diseases causing high levels of morbidity and mortality in 
endemic areas, mainly in tropical and subtropical regions of the world [5]. Brazil, India, Bangladesh, Sudan, South Sudan and Ethiopia concentrate $90 \%$ of the global incidence of visceral leishmaniasis (VL), whereas Afghanistan, Algeria, Colombia, Brazil, Iran, Syria, Ethiopia, Sudan, Costa Rica and Peru concentrate $\sim 75 \%$ of the global incidence of cutaneous leishmaniasis (CL) [5].

An important factor influencing the dynamics of Leishmania parasite transmission in endemic areas is the feeding behaviour of female sand flies. For example, to be considered a 'good vector' for zoonotic Leishmania parasites, females from a given sand fly species should feed frequently on the reservoir host(s) and on humans as well. Therefore, investigations of the blood meals of various species of sand flies are crucial towards a better assessment of the risk of Leishmania transmission in areas where leishmaniasis are endemic. Several methodologies to identify blood meal in sand flies have been used, including enzyme-linked immunosorbent assay (ELISA), mass spectrometry, precipitin test and polymerase chain reaction (PCR) [6-11]. More recently, quantitative real-time PCR $[12,13]$ and PCR followed by amplicon sequencing [14] demonstrated promising results, with high-level sensitivity. Although all these methods generated important information about the feeding behaviour of sand flies, they may present several drawbacks, such as low sensitivity and specificity (e.g. ELISA and precipitin test) and high cost (e.g. mass spectrometry and PCR followed by amplicon sequencing) [12, $15,16]$.

In this context, we developed a fast multiplex real-time PCR assay for simultaneous detection of dog and human blood meals and Leishmania parasites in sand flies, with high analytical sensitivity and specificity, as well as relatively low cost.

\section{Methods}

\section{Blood samples and Leishmania parasites}

Venous blood samples $(2 \mathrm{ml})$ were withdrawn from a dog and a human in EDTA tubes (Vacuette K3EDTA tube; Greiner Bio-One, Kremsmünster, Austria) and frozen at $-20{ }^{\circ} \mathrm{C}$ until DNA extraction. Reference strains of Leishmania infantum (MHOM/BR/76/M4192) and Leishmania braziliensis (MHOM/BR/1975/M2903) were obtained from the Leishmaniasis Reference Service of the Aggeu Magalhães Institute (Fiocruz-PE, Recife, Brazil). Both blood samples and Leishmania parasites were used for the preparation of standard curves (see below). Additionally, two non-engorged females of Migonemyia migonei obtained from a laboratory colony established in the Aggeu Magalhães Institute (Fiocruz-PE) were used as negative controls.

\section{Nucleic acid extraction}

DNA extraction from sand flies, blood samples and Leishmania parasites was performed using DNeasy Blood \& Tissue kit (Qiagen, Hilden, Germany), according to the manufacturer's instructions. All samples were eluted in $100 \mu \mathrm{l}$ of buffer AE (10 mM Tris Cl, $0.5 \mathrm{mM}$ EDTA, pH 9.0), properly labelled and frozen at $-20{ }^{\circ} \mathrm{C}$. The quantity and purity (absorbance ratio at $260 / 280 \mathrm{~nm}$ and at $260 / 230 \mathrm{~nm}$ ) of the extracted DNA were accessed using a NanoDrop Lite spectrophotometer (Thermo Fisher Scientific, Waltham, USA).

\section{Primer and probe design}

Primers and TaqMan hydrolysis probes (Table 1) targeting dog and human DNA were developed based on the sequences of the mitochondrial cytochrome $c$ oxidase subunit 1 (cox 1$)$ and cytochrome $b$ (cytb) genes, respectively, available from GenBank (accession numbers: NC_002008.4 and NC_012920.1), using the Primer3 v.0.4.0 (http://bioinfo.ut.ee/primer3-0.4.0/primer3/). Primers and probes were designed following the instructions of the TaqMan Multiplex Optimization User Guide [17] for optimum assay efficiency. In particular, primers should have a GC content of $40-60 \%$ and generate amplicons of 50-150 bp. The melting temperature $\left(T_{\mathrm{m}}\right)$ should be similar for all primers; the $T_{\mathrm{m}}$ of the probes be $\sim 10{ }^{\circ} \mathrm{C}$ higher than the $T_{\mathrm{m}}$ of the primers. With that in

Table 1 Primers and TaqMan probes used in the singleplex and multiplex real-time PCR assays

\begin{tabular}{|c|c|c|c|c|c|}
\hline Species & Target & Primers and probes & Sequence $\left(5^{\prime}-3^{\prime}\right)$ & Product size (bp) & References \\
\hline \multirow[t]{3}{*}{ Canis familiaris } & \multirow[t]{3}{*}{ cox1 gene } & KF/CF-F (forward) & GGGGCTTTGGAAACTGACTA & \multirow[t]{3}{*}{95} & \multirow[t]{3}{*}{ Present study } \\
\hline & & KF/CF-R (reverse) & TGGAGGAAGGAGTCAGAAGC & & \\
\hline & & KF/CF-P (probe) & VIC-ATTGGTGCTCCGGACATGGCAT-QSY & & \\
\hline \multirow[t]{3}{*}{ Homo sapiens } & \multirow[t]{3}{*}{ cytb gene } & KF/HS-F (forward) & CCACCCTCACACGATTCTTT & \multirow[t]{3}{*}{104} & \multirow[t]{3}{*}{ Present study } \\
\hline & & KF/HS-R (reverse) & GTTGTTTGATCCCGTTTCGT & & \\
\hline & & KF/HS-P (probe) & NED-TGCAGCCCTAGCAACACTCCACC-NFQ-MGB & & \\
\hline \multirow[t]{3}{*}{ Leishmania spp. } & \multirow[t]{3}{*}{ kDNA } & LEISH-1 (forward) & AACTTTTCTGGTCCTCCGGGTAG & \multirow[t]{3}{*}{120} & \multirow[t]{3}{*}[18]{} \\
\hline & & LEISH-2 (reverse) & ACCCCCAGTTTCCCGCC & & \\
\hline & & TaqMan-MGB (probe) & FAM-AAAAATGGGTGCAGAAAT-NFQ-MGB & & \\
\hline
\end{tabular}


mind, primers (18-20 bp) and probes (13-25 bp) were designed to have $T_{\mathrm{m}}$ of $58-60{ }^{\circ} \mathrm{C}$ and $68-70{ }^{\circ} \mathrm{C}$, respectively (Table 1).

To avoid non-specific amplification, primers were submitted to BLAST $/ \mathrm{n}$ of the National Centre for Biotechnology Information (NCBI) to verify its specificity. Furthermore, the formation of dimmers, hairpins, and $T_{\mathrm{m}}$ were assessed with the OligoAnalyzer 3.1 software (https ://eu.idtdna.com/calc/analyzer). The primers LEISH-1 and LEISH-2 and a TaqMan probe (Table 1) were used to detect a $120 \mathrm{bp}$ fragment of the Leishmania minicircle kinetoplast DNA (kDNA) [18].

\section{Optimization of singleplex real-time PCR assays}

Before optimizing the multiplex real-time PCR assay, singleplex real-time PCR assays were optimized to specifically detect dog and human DNA. Additionally, a singleplex real-time PCR assay targeting kDNA was performed as described elsewhere [19]. A dilution matrix was made to determine optimal concentration of primers and probes [17]. The reaction mixture contained 1.35 $\mu \mathrm{l}$ of each primer (final concentration of $900 \mathrm{nM}$ each), $0.3 \mu \mathrm{l}$ of the probe $(200 \mathrm{nM}), 2.5 \mu \mathrm{l}$ of water (DNAse and RNAse free), $7.5 \mu \mathrm{l}$ of TaqMan Fast Advanced Master Mix (Thermo Fisher Scientific) and 2- $\mu$ l sample DNA, in a final volume of $15 \mu \mathrm{l}$. Positive controls consisted DNA extracted from dog and human blood and from cultured promastigotes of $L$. infantum, whereas a master mix without DNA and DNA from unfed female sand flies were used as no template control (NTC) and negative control, respectively. The real-time PCR thermal conditions were as follows: $20 \mathrm{~s}$ at $95^{\circ} \mathrm{C}$ followed by 35 cycles of $1 \mathrm{~s}$ at $95^{\circ} \mathrm{C}$ and $20 \mathrm{~s}$ at $60^{\circ} \mathrm{C}$ (estimated running time: $33.5 \mathrm{~min}$ ). All singleplex real-time PCRs were performed on a QuantStudio 5 Real-Time PCR system (Thermo Fisher Scientific), with automatic baseline and threshold settings. The reactions were performed in triplicate, with inconsistent or undetermined results between the replicates being regarded as negative.

\section{Optimization of the multiplex real-time PCR assay}

Sets of primers and probes targeting dog coxl, human $c y t b$ and Leishmania kDNA were multiplexed by labelling each probe with a different dye (Table 1$)$. The reaction mixture consisted of $0.675 \mu \mathrm{l}$ of each primer $(900 \mathrm{nM})$, $0.15 \mu \mathrm{l}$ of each probe $(200 \mathrm{nM}), 7.5 \mu \mathrm{l}$ of TaqMan $^{\circledR}$ Fast Advanced Master Mix (Applied Biosystems) and 3- $\mu \mathrm{l}$ sample DNA, in a final volume of $15 \mu$ l. Positive controls consisted of mixed DNA extracted from dog and human blood and cultured promastigotes of L. infantum. Negative controls and thermal cycling conditions employed in the multiplex assay were the same used in the singleplex assays. All the three channels (reporter and quencher) for VIC-QSY, NED-NFQ/MGB and FAM-NFQ were selected. All multiplex real-time PCR assays were run on a QuantStudio 5 Real-Time PCR system (Thermo Fisher Scientific), with automatic baseline and threshold settings. The reactions were performed in triplicate and repeated three times, with inconsistent or undetermined results between the replicates being regarded as negative.

\section{Specificity, sensitivity, linearity and reproducibility}

An in silico analysis of the specificity of the primers and probes was checked using program BLAST/n. The analytical specificity was assessed through cross-tests between the targets (dog, human, L. braziliensis and $L$. infantum) and unfed female sand flies. Standard curves were prepared using nine serial dilutions $\left(10^{8}, 10^{7}, 10^{6}\right.$, $10^{5}, 10^{4}, 10^{3}, 10^{2}, 10^{1}$ and $10^{0} \mathrm{fg}$ per reaction) of DNA from dog, human and L. infantum to assess the analytical sensitivity (detection limit) of the assays. The analytical sensitivity was defined as the lowest amount of DNA detectable in a given assay. The cut-off point of an assay was defined as the quantification cycle $(\mathrm{Cq})$ value corresponding to the detection limit [20].

The amplification efficiency $(E)$ was calculated using the slope of the regression line in the standard curve through the equation: $E=10^{(-1 / \text { slope })}-1$. A slope close to -3.33 was considered optimal. The correlation coefficient $\left(R^{2}\right)$ value was automatically calculated using measure of the closeness of fit between the regression line and the individual $\mathrm{Cq}$ data points of the standard reactions [21]. The y-intercept value also automatically calculated and corresponds to the theoretical $\mathrm{Cq}$ value for a single copy of the target molecule. In intra-assays, triplicates were made in the same plate, whereas in inter-assay, triplicates were repeated in three independent assays performed in three different days within a week.

\section{Assay of field-collected sand flies}

A total of 97 engorged female sand flies collected in the context of a previous study [22] were tested individually by the newly developed multiplex real-time PCR. These females belonged to two species: M. migonei $(n=$ 95); and Nyssomyia intermedia $(n=2)$. Details regarding sand fly collection, identification and processing are described elsewhere [22]. Females were collected both indoors $(n=23)$ and outdoors $(n=74)$.

\section{Data analysis}

Real-time PCR results were analysed using QuantStudio Design and Analysis Software 1.3.1 (Thermo Fisher Scientific). To assess intra- and inter-assay reproducibility, the percent coefficient of variation $(\% \mathrm{CV})$ was calculated for each set of triplicate reactions. The positivity rates 
for Leishmania parasites in female sand flies collected indoors and outdoors was compared using Fisher's exact test, considering $P<0.05$ as statistically significant. Statistical analysis and calculations were performed using GraphPad Prism 5.0 software (GraphPad Software Inc., CA, USA).

\section{Results}

\section{Specificity, sensitivity and linearity of the singleplex} and multiplex assays

The sets of primers and probes specific for dog cox 1 , human $c y t b$ and Leishmania kDNA detected only the expected target. Moreover, they did not produce any non-specific amplification in the cross-testing with nontarget DNA, or with no template and negative controls. Likewise, there were no false positives due to cross-talk between dye signals from each assay. Thus, analytical specificity of the assays was considered to be $100 \%$.

The analytical sensitivity of the singleplex real-time PCR assays for $\operatorname{dog} \operatorname{cox} 1$ and human $c y t b$ was $1000 \mathrm{fg}$, with $\mathrm{Cq}$ values of $34.2 \pm 0.4$ and $33.2 \pm 0.1$, respectively.

Table 2 Analytical sensitivity and corresponding threshold cycle (Cq) values from singleplex and multiplex real-time PCR assays for each target

\begin{tabular}{llll}
\hline DNA sample & $\begin{array}{l}\text { Quantity }(\mathrm{fg} / \\
\text { reaction })\end{array}$ & \multicolumn{2}{l}{ Cq value (mean \pm SD) } \\
\cline { 3 - 4 } & & Singleplex & Multiplex \\
\hline Canis familiaris & $10^{8}$ & $17.92 \pm 0.17$ & $17.91 \pm 0.15$ \\
& $10^{7}$ & $21.14 \pm 0.06$ & $20.38 \pm 0.99$ \\
& $10^{6}$ & $24.43 \pm 0.04$ & $23.80 \pm 0.04$ \\
& $10^{5}$ & $27.79 \pm 0.10$ & $27.09 \pm 0.20$ \\
& $10^{4}$ & $31.09 \pm 0.11$ & $30.14 \pm 0.19$ \\
Homo sapiens & $10^{3}$ & $34.21 \pm 0.40$ & $33.14 \pm 1.03$ \\
& $10^{8}$ & $17.81 \pm 0.05$ & $16.11 \pm 0.31$ \\
& $10^{7}$ & $20.84 \pm 0.12$ & $18.34 \pm 0.14$ \\
& $10^{6}$ & $24.12 \pm 0.04$ & $21.73 \pm 0.58$ \\
& $10^{5}$ & $27.43 \pm 0.08$ & $25.31 \pm 0.23$ \\
& $10^{4}$ & $30.55 \pm 0.24$ & $27.90 \pm 0.37$ \\
& $10^{3}$ & $33.20 \pm 0.07$ & $30.59 \pm 0.28$ \\
& $10^{8}$ & $8.64 \pm 0.05$ & $9.18 \pm 0.31$ \\
& $10^{7}$ & $12.38 \pm 0.10$ & $11.43 \pm 0.14$ \\
& $10^{6}$ & $15.51 \pm 0.12$ & $14.61 \pm 0.06$ \\
& $10^{5}$ & $19.11 \pm 0.04$ & $17.88 \pm 0.16$ \\
& $10^{4}$ & $22.63 \pm 0.07$ & $21.45 \pm 0.17$ \\
& $10^{3}$ & $26.20 \pm 0.02$ & $24.44 \pm 0.23$ \\
& $10^{2}$ & $29.77 \pm 0.13$ & $27.46 \pm 0.05$ \\
& $10^{1}$ & $32.33 \pm 0.23$ & $30.88 \pm 0.25$ \\
& $10^{0}$ & $33.49 \pm 0.09$ & $33.11 \pm 0.25$ \\
\hline A & &
\end{tabular}

Abbreviation: SD, standard deviation
Conversely, the analytical sensitivity for Leishmania kDNA was $1 \mathrm{fg}(\mathrm{Cq}=33.5 \pm 0.1)$ (Table 2).

The linear regression analysis of standard curves confirmed linearity of the singleplex real-time PCR assays for $\operatorname{dog} \operatorname{cox} 1\left(R^{2}=0.999, E=101.9\right.$, slope $=-3.28$, y-intercept $=44.1)$, human cytb $\left(R^{2}=0.999, E=108.9\right.$, slope $=-3.12$, y-intercept $=42.8)$ and Leishmania $\mathrm{kDNA}\left(R^{2}\right.$ $=0.991, E=103.5$, slope $=-3.24$, y-intercept $=35.2)$ (Fig. 1).

Similar results were found with the multiplex real-time PCR assay, the detection limits for dog $\operatorname{cox} 1$ and human $c y t b$ being $1000 \mathrm{fg}$, with Cq values of $33.1 \pm 1.0$ and 30.6 \pm 0.3 , respectively. The detection limit for Leishmania kDNA was $1 \mathrm{fg}(\mathrm{Cq}=33.1 \pm 0.3)$ (Table 2). Similarly, the linear regression analysis of standard curves confirmed linearity of the multiplex real-time PCR assay for dog $\operatorname{cox} 1\left(R^{2}=0.996, E=109.8\right.$, slope $=-3.11$, y-intercept $=$ 42.5), human $c y t b\left(R^{2}=0.993, E=116.0\right.$, slope $=-2.99$, y-intercept $=39.8)$ and Leishmania kDNA $\left(R^{2}=0.998, E\right.$ $=109.9$, slope $=-3.10$, y-intercept $=33.6)($ Fig. 2).

\section{Reproducibility of multiplex real-time PCR assay}

The variability of the multiplex real-time PCR assay was assessed between and within runs based on standard curves. The coefficients of variation values of intra- and inter- assays were in the range of $0.16-4.01 \%$ (Table 3) and $0.92-7.44 \%$ (Table 4), respectively. Overall, the difference between $\mathrm{Cq}$ values intra- and inter-assay was $\leq$ 2 , suggesting that the multiplex real-time PCR assay is reliable.

\section{Evaluation of multiplex real-time PCR assay with field-collected sand flies}

Fifty out of 97 (51.6\%) engorged female sand flies tested by the multiplex real-time PCR assay were positive. All positive females belonged to the species $M$. migonei.

Forty $(80.0 \%)$ females were positive for one target (i.e. human $c y t b, \operatorname{dog} c o x 1$ or Leishmania kDNA) and $10(20.0 \%)$ for two targets. Among females that were positive for one target $(n=40), 85.0 \%$ were positive for human $c y t b, 10.0 \%$ for Leishmania kDNA and $5.0 \%$ for dog cox 1 . Among those positive for two targets $(n=10)$, $80.0 \%$ were simultaneously positive for human $c y t b$ and Leishmania kDNA and $20.0 \%$ were simultaneously positive for human $c y t b$ and $\operatorname{dog} \operatorname{cox} 1$.

Out of 12 Leishmania-positive females, eight were fed on humans and none were fed on dogs. Four positive females were collected indoors and eight outdoors (Fisher's exact test, $P=0.4704$ ). 


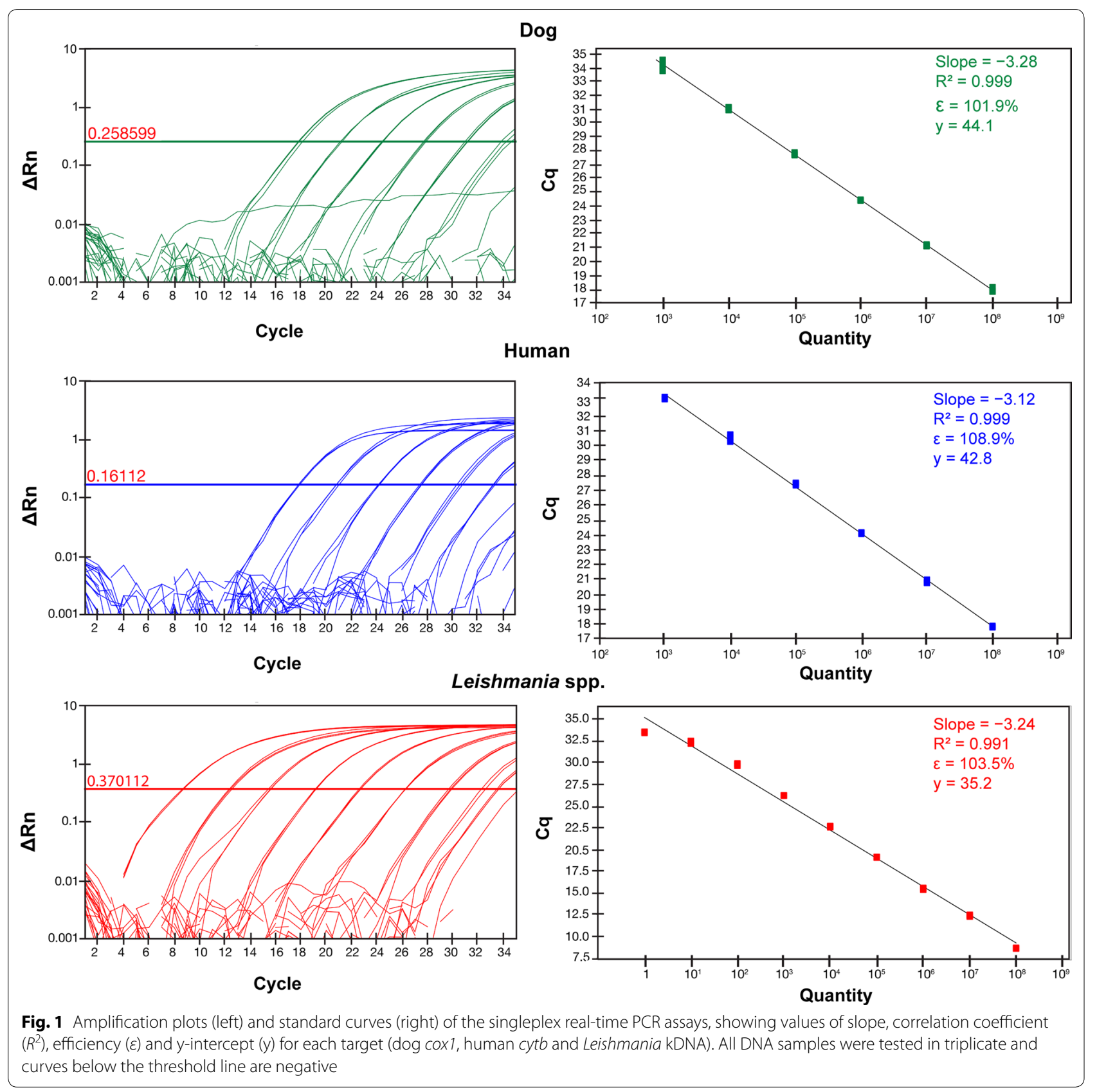

\section{Discussion}

In this study, we were interested in developing a tool that could generate information about role of sand flies collected inside human houses and surrounding areas in the transmission of Leishmania parasites to dogs and humans. Hence, we developed a TaqMan-based fast multiplex quantitative real-time PCR assay for the simultaneous detection of $\operatorname{dog} c o x 1$, human $c y t b$ and Leishmania kDNA in female sand flies. The addition of multiple primers and probes in a single reaction as well as changes in the number of cycles and annealing temperature can affect the specificity, sensitivity and efficiency of real-time PCR assays [23, 24]. This is in fact one of the main obstacles to overcome while developing a multiplex real-time PCR assay [17]. Although many singleplex assays have been successful in identifying blood meal and Leishmania parasites in sand flies [12-15, 25], none of them combined the detection of different host and the parasite DNA in a one-step assay. The development of the multiplex real-time PCR assay proposed 

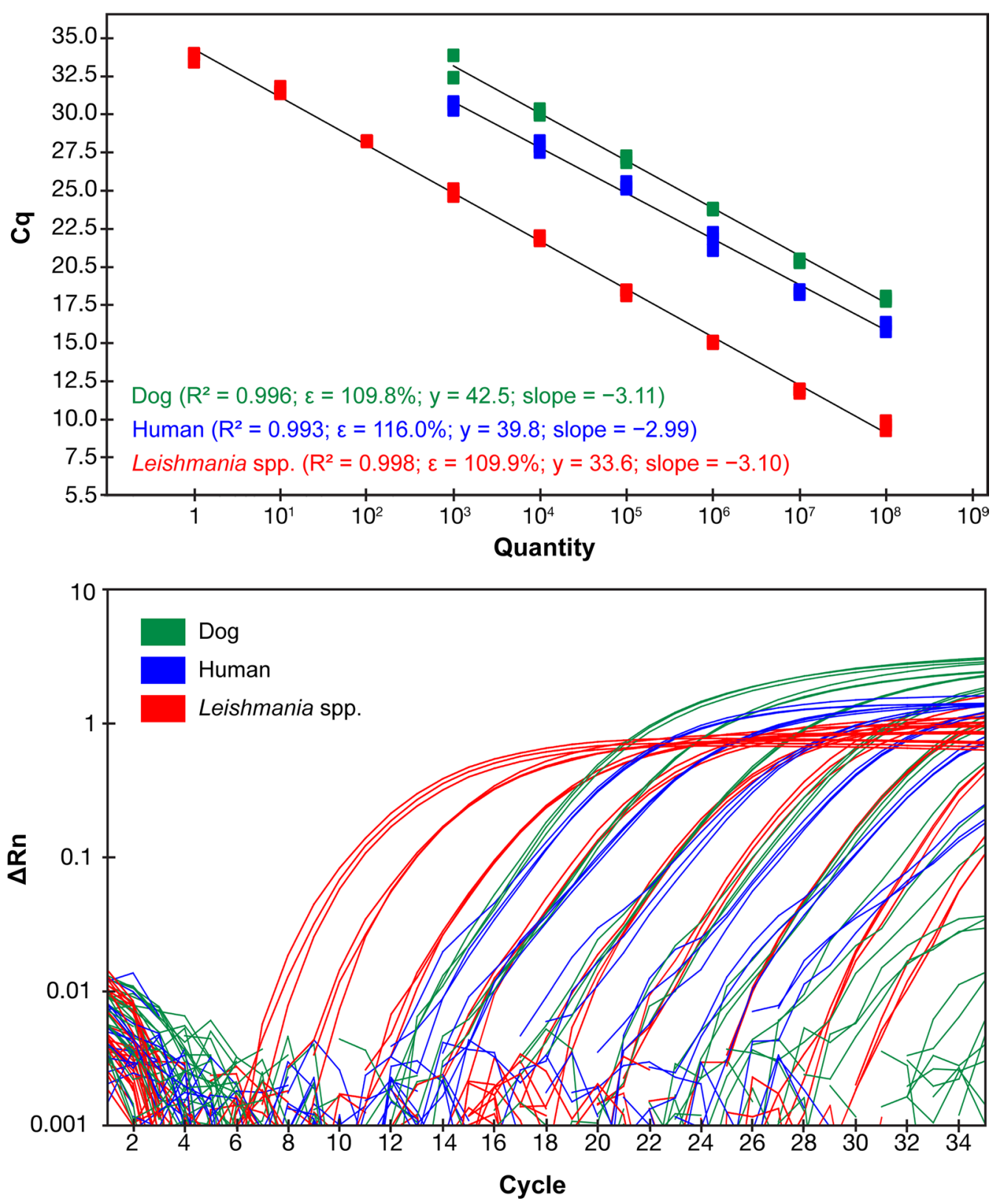

Fig. 2 Standard curve (top) and amplification plot (bottom) of the multiplex real-time PCR assay, showing values of slope, correlation coefficient $\left(R^{2}\right)$, efficiency $(\varepsilon)$ and $y$-intercept $(y)$ for each target (dog, human and Leishmania DNA). All DNA samples were tested in triplicate

by the present study resulted in a series of advantages compared to other assays, such as the reduction in reagent consumption, labour time and the ability to provide faster results (considering that regular real-time PCR assays take over 1 hour to complete, e.g. 90 min [12, 18], $78 \mathrm{~min}[13])$. In practice, this assay allows testing a great number of sand flies for both dog cox1, human $c y t b$ and Leishmania kDNA in a shorter period of time $(\sim 34$ $\mathrm{min}$ ), reducing overall costs.
Considering that female sand flies consume a small amount of blood $(\leq 1 \mu \mathrm{l})$ during blood-feeding [26], one of the main technical challenges while developing a molecular tool for detecting host blood and Leishmania parasites is the necessity to detect and quantify a very limited amount of DNA [16]. In fact, the sensitivity of such an assay depends directly on both the initial quantity of the target DNA in the sample and on the time span from blood ingestion, as there is a progressive 
Table 3 Intra-assay reproducibility of the multiplex real-time PCR assay

\begin{tabular}{|c|c|c|c|c|c|c|}
\hline \multirow[t]{2}{*}{ DNA sample } & \multirow[t]{2}{*}{ Quantity (fg/reaction) } & \multicolumn{3}{|c|}{ Cqvalue } & \multirow[t]{2}{*}{ Mean \pm SD } & \multirow[t]{2}{*}{$\% C V$} \\
\hline & & $\mathrm{R} 1$ & R2 & R3 & & \\
\hline \multirow[t]{6}{*}{ Canis familiaris } & $10^{8}$ & 17.27 & 17.27 & 17.01 & $17.18 \pm 0.15$ & 0.87 \\
\hline & $10^{7}$ & 19.23 & 19.17 & 19.30 & $19.24 \pm 0.06$ & 0.33 \\
\hline & $10^{6}$ & 22.98 & 22.22 & 21.73 & $22.31 \pm 0.63$ & 2.82 \\
\hline & $10^{5}$ & 25.06 & 25.44 & 26.14 & $25.55 \pm 0.55$ & 2.15 \\
\hline & $10^{4}$ & 28.94 & 29.02 & 28.74 & $28.90 \pm 0.15$ & 0.51 \\
\hline & $10^{3}$ & 33.61 & 32.99 & 34.48 & $33.69 \pm 0.75$ & 2.22 \\
\hline \multirow[t]{6}{*}{ Homo sapiens } & $10^{8}$ & 16.67 & 16.99 & 16.87 & $16.84 \pm 0.16$ & 0.96 \\
\hline & $10^{7}$ & 18.76 & 18.74 & 18.87 & $18.79 \pm 0.07$ & 0.39 \\
\hline & $10^{6}$ & 22.50 & 22.35 & 22.74 & $22.53 \pm 0.20$ & 0.88 \\
\hline & $10^{5}$ & 25.87 & 25.57 & 25.72 & $25.72 \pm 0.15$ & 0.58 \\
\hline & $10^{4}$ & 28.48 & 28.52 & 27.83 & $28.27 \pm 0.38$ & 1.36 \\
\hline & $10^{3}$ & 30.94 & 33.24 & 33.13 & $32.44 \pm 1.30$ & 4.01 \\
\hline \multirow[t]{9}{*}{ Leishmania spp. } & $10^{8}$ & 5.96 & 5.92 & 6.06 & $5.98 \pm 0.07$ & 1.23 \\
\hline & $10^{7}$ & 8.58 & 8.87 & 9.16 & $8.87 \pm 0.29$ & 3.28 \\
\hline & $10^{6}$ & 12.54 & 12.22 & 12.56 & $12.44 \pm 0.19$ & 1.53 \\
\hline & $10^{5}$ & 15.81 & 15.58 & 16.32 & $15.91 \pm 0.38$ & 2.39 \\
\hline & $10^{4}$ & 19.31 & 19.43 & 19.78 & $19.51 \pm 0.25$ & 1.26 \\
\hline & $10^{3}$ & 23.16 & 23.06 & 22.72 & $22.98 \pm 0.23$ & 1.02 \\
\hline & $10^{2}$ & 26.66 & 26.21 & 26.78 & $26.55 \pm 0.30$ & 1.13 \\
\hline & $10^{1}$ & 29.82 & 29.91 & 29.83 & $29.85 \pm 0.05$ & 0.16 \\
\hline & $10^{0}$ & 32.03 & 32.10 & 32.52 & $32.22 \pm 0.26$ & 0.81 \\
\hline
\end{tabular}

Abbreviations: Cq, quantification cycle; R, replicate; SD, standard deviation; \%CV, percent coefficient of variation

degradation of the host DNA during blood digestion [12, 16, 27]. The multiplex real-time PCR assay developed in this study was shown to be specific and highly sensitive, without interference and competition between targets and dyes. Particularly, identical analytical sensitivities were obtained with singleplex and multiplex assays (i.e. $10^{3} \mathrm{fg} /$ reaction for $\operatorname{dog} c o x 1$ and human $c y t b$, and $1 \mathrm{fg}$ for Leishmania kDNA). These results are similar to those obtained with other assays for detecting blood meals of female sand flies, which reported a detection limit from $10^{2} \mathrm{fg}$ to $10^{4} \mathrm{fg}$ of host DNA [6, 12, 27]. More recently, two SYBR Green-based real-time PCR assays were reported to have a detection limit of $26 \mathrm{fg}$ for dog and 84 fg for human [13]. Despite the good analytical sensitivity of these assays, when non-target DNA samples were used some slight noise was reported in the melting curve analysis, though with a $\mathrm{Cq}$ value always higher than 30 [13]. In fact, non-specific signals are a known limiting factor of some SYBR Green-based real-time PCR assays $[12,28]$, which may eventually obscure the interpretation of the results. The use of hydrolysis probes (e.g. TaqMan probes) may increase the specificity of real-time PCR assays as demonstrated elsewhere $[29,30]$.

For Leishmania kDNA detection, the analytical sensitivity of our multiplex real-time PCR was similar to a singleplex assay using the same primers and probe [19], allowing the detection of less than a single parasite per sample. This high sensitivity may be partly attributed to the target used (i.e. kDNA), which is present in high number of copies $(\sim 10,000$ copies of minicircle molecules) per parasite [31]. In fact, other real-time PCR assays using the same target gene also reported very good analytical sensitivity [32, 33].

Our multiplex real-time PCR assay was also successfully applied in field-collected samples. A total of 44 females of $M$. migonei (stored at $-20{ }^{\circ} \mathrm{C}$ for $\sim 2$ years) were positive for human blood. This sand fly species displays a remarkable degree of anthropophily, and it is a proven vector of $L$. braziliensis and a putative vector of L. infantum in Latin America [34, 35]. Interestingly, eight out of 44 females fed on humans were also positive for Leishmania spp. Leishmania-positive sand flies were collected in human dwellings (four indoors and eight outdoors), where human cases of CL by L. braziliensis were previously recorded [22]. Altogether, these findings strongly suggest that $M$. migonei is a vector of $L$. braziliensis for humans in the indigenous villages, where sand flies were collected. While our multiplex real-time PCR assay was tested with sand flies collected from a CL focus, it is also suitable for other epidemiological settings, 
Table 4 Inter-assay reproducibility of the multiplex real-time PCR assay

\begin{tabular}{|c|c|c|c|c|c|c|}
\hline \multirow[t]{2}{*}{ DNA sample } & \multirow[t]{2}{*}{ Quantity (fg/reaction) } & \multicolumn{3}{|c|}{ Cq value (mean) } & \multirow[t]{2}{*}{ Mean \pm SD } & \multirow[t]{2}{*}{$\% C V$} \\
\hline & & D1 & D2 & D3 & & \\
\hline \multirow[t]{6}{*}{ Canis familiaris } & $10^{8}$ & 17.18 & 17.61 & 17.29 & $17.36 \pm 0.23$ & 1.30 \\
\hline & $10^{7}$ & 19.24 & 19.80 & 19.38 & $19.47 \pm 0.29$ & 1.51 \\
\hline & $10^{6}$ & 22.31 & 23.30 & 22.80 & $22.8 \pm 0.50$ & 2.17 \\
\hline & $10^{5}$ & 25.55 & 26.62 & 26.18 & $26.12 \pm 0.54$ & 2.07 \\
\hline & $10^{4}$ & 28.90 & 29.95 & 29.57 & $29.47 \pm 0.53$ & 1.80 \\
\hline & $10^{3}$ & 33.69 & 34.42 & 33.54 & $33.88 \pm 0.47$ & 1.39 \\
\hline \multirow[t]{6}{*}{ Homo sapiens } & $10^{8}$ & 16.84 & 15.51 & 16.43 & $16.26 \pm 0.68$ & 4.19 \\
\hline & $10^{7}$ & 18.79 & 17.57 & 18.18 & $18.18 \pm 0.61$ & 3.35 \\
\hline & $10^{6}$ & 22.53 & 21.30 & 21.86 & $21.90 \pm 0.62$ & 2.82 \\
\hline & $10^{5}$ & 25.72 & 24.95 & 25.33 & $25.33 \pm 0.39$ & 1.53 \\
\hline & $10^{4}$ & 28.27 & 27.65 & 27.78 & $27.90 \pm 0.33$ & 1.18 \\
\hline & $10^{3}$ & 32.44 & 32.21 & 31.78 & $32.14 \pm 0.34$ & 1.04 \\
\hline \multirow[t]{9}{*}{ Leishmania spp. } & $10^{8}$ & 5.98 & 6.76 & 6.86 & $6.53 \pm 0.48$ & 7.37 \\
\hline & $10^{7}$ & 8.87 & 9.95 & 10.24 & $9.68 \pm 0.72$ & 7.44 \\
\hline & $10^{6}$ & 12.44 & 13.48 & 13.77 & $13.23 \pm 0.70$ & 5.28 \\
\hline & $10^{5}$ & 15.91 & 16.91 & 17.47 & $16.76 \pm 0.79$ & 4.73 \\
\hline & $10^{4}$ & 19.51 & 20.50 & 20.87 & $20.29 \pm 0.70$ & 3.47 \\
\hline & $10^{3}$ & 22.98 & 24.02 & 24.84 & $23.95 \pm 0.93$ & 3.89 \\
\hline & $10^{2}$ & 26.55 & 27.43 & 25.47 & $26.48 \pm 0.98$ & 3.71 \\
\hline & $10^{1}$ & 29.85 & 30.40 & 30.33 & $30.20 \pm 0.30$ & 0.99 \\
\hline & $10^{\circ}$ & 32.22 & 32.37 & 32.79 & $32.46 \pm 0.30$ & 0.92 \\
\hline
\end{tabular}

Notes: In each day, DNA samples were tested in triplicate (mean values reported)

Abbreviations: Cq, quantification cycle; D, day; SD, standard deviation; \%CV, percent coefficient of variation

namely VL endemic regions, considering that the primers and probe used also efficiently detected $L$. infantum kDNA $[18,19]$.

The identification of humans as the most frequent host of $M$. migonei females in this study, also reinforces their high attractiveness for humans [34] as well as the hypothesis that this species may be adapted to feed indoors [22]. It has been shown that human CL patients that have been treated and clinically cured may harbour viable parasites in their scars [36] and it has been suggested that they could eventually act as a source of infection to sand flies [37]. Our multiplex real-time PCR assay may be a useful tool to assess the presence of Leishmania parasites and human blood in sand flies from other CL-endemic areas, ultimately to investigate their possible role in the transmission cycle of $L$. braziliensis.

The finding of eight Leishmania-positive females which previously fed on humans raises interesting questions regarding whether these females acquired the infection from a previous unknown host (e.g. small rodents) [38] or from humans themselves. Interestingly, four Leishmania-positive engorged female sand flies did not apparently feed on humans or dogs, further suggesting that they probably acquired the parasites from another host.

\section{Conclusions}

In conclusion, a novel TaqMan-based fast multiplex real-time PCR assay was developed, optimized and validated herein for simultaneous detection of dog and human blood meals and Leishmania parasites in female sand flies. This assay may represent a tool for assessing Leishmania parasite infection in female sand flies and for investigating whether and how often these females feed on dogs and humans, thereby allowing estimation of the risk of infection in these hosts.

\section{Abbreviations}

VL: visceral leishmaniasis; CL: cutaneous leishmaniasis; PCR: polymerase chain reaction; ELISA: enzyme-linked immunosorbent assay; EDTA: ethylene diamine tetra acetic acid; DNA: deoxyribonucleic acid; kDNA: kinetoplast minicircle DNA; cox1: mitochondrial cytochrome c oxidase subunit 1 gene; cytb: cytochrome b gene; GC: guanine/cytosine; BLAST: Basic Local Alignment Search Tool; NCBI: National Center for Biotechnology Information; NTC: no template control; Tm: melting temperature; Cq: quantification cycle; $\triangle \mathrm{Rn}$ : delta $\mathrm{Rn}$; E: efficiency; \%CV: percent coefficient of variation; SD: standard deviation.

\section{Acknowledgements}

Thanks to the Leishmaniasis Reference Service of the Aggeu Magalhães Institute (Fiocruz-PE), Brazil, for proving us with the reference strains of $L$. infantum and L. braziliensis. Publication of this paper has been sponsored by Bayer Animal Health in the framework of the 15 th $C V B D^{\circledR}$ World Forum Symposium. 


\section{Authors' contributions}

KGSS and FDT conceived and designed the experiments. KGSS conducted the laboratory work. DEOM and LAF contributed to sample collection. MHSP, DO, KGSS and FDT performed the data analysis. KGSS and FDT wrote the paper. All authors read and approved the final manuscript.

\section{Funding}

This study was financially supported by Fundação de Amparo à Ciência e Tecnologia de Pernambuco (FACEPE - APQ-0281-2.13/13). FDT is the recipient of a research fellowship from Conselho Nacional de Desenvolvimento Científico e Tecnológico (CNPq; 313118/2018-3).

\section{Availability of data and materials}

The data supporting the conclusions of this article are included within the article. Raw data can be shared with other researchers upon a specific request.

\section{Ethics approval and consent to participate}

All methods were carried out in accordance with the recommendations of the Brazilian National Council of Animal experimentation (CONCEA) and Brazilian ethical guidelines for research involving humans (resolution: 466/2012). All experimental protocols were reviewed and approved by the Animal Ethics Committee (CEUA: 100/2016) and Research Ethics Committee (CEP. 56276916.0.0000.5190) of the Aggeu Magalhães Institute (Fiocruz-PE). Before blood collection, written informed consent was obtained from the human subject and from the dog owner, both of whom were adults.

\section{Consent for publication}

Not applicable.

\section{Competing interests}

The authors declare that they have no competing interests.

\section{Author details}

${ }^{1}$ Department of Immunology, Aggeu Magalhães Institute, Oswaldo Cruz Foundation (Fiocruz), Recife, Brazil. ${ }^{2}$ Federal University of Pernambuco (UFPE), Caruaru, Brazil. ${ }^{3}$ Department of Entomology, Aggeu Magalhães Institute, Oswaldo Cruz Foundation (Fiocruz), Recife, Brazil. ${ }^{4}$ Department of Veterinary Medicine, Università degli Studi di Bari, Valenzano, Bari, Italy. ${ }^{5}$ Faculty of Veterinary Sciences, Bu-Ali Sina University, Hamedan, Iran.

Received: 21 November 2019 Accepted: 24 February 2020 Published online: 21 April 2020

\section{References}

1. Maroli M, Feliciangeli MD, Bichaud L, Charrel RN, Gradoni L. Phlebotomine sandflies and the spreading of leishmaniases and other diseases of public health concern. Med Vet Entomol. 2013;27:123-47.

2. Schlein Y, Jacobson RL, Müller GC. Sand fly feeding on noxious plants: a potential method for the control of leishmaniasis. Am J Trop Med Hyg. 2001;65:300-3.

3. Killick-Kendrick R. The biology and control of phlebotomine sand flies. Clin Dermatol. 1999;17:279-89.

4. Shimabukuro PHF, de Andrade AJ, Galati EAB. Checklist of American sand flies (Diptera, Psychodidae, Phlebotominae): genera, species, and their distribution. ZooKeys. 2017;8:67-106.

5. Alvar J, Vélez ID, Bern C, Herrero M, Desjeux P, Cano J, et al. Leishmaniasis worldwide and global estimates of its the incidence. PLOS ONE. 2012;7:e35671.

6. Abbasi I, Cunio R, Warburg A. Identification of blood meals imbibed by phlebotomine sand flies using cytochrome $b$ PCR and reverse line blotting. Vector Borne Zoonotic Dis. 2009;9:79-86.

7. Fonteles RS, Vasconcelos GC, Azevêdo PC, Lopes GN, Moraes JL, Lorosa $E S$, et al. Blood feeding preference of Lutzomyia whitmani (Diptera, Psychodidae) in a transmission area for American cutaneous leishmaniasis in the State of Maranhão. Brazil. Rev Soc Bras Med Trop. 2009;42:647-50.

8. Afonso MMS, Duarte R, Miranda JC, Caranha L, Rangel EF. Studies on the feeding habits of Lutzomyia (Lutzomyia) longipalpis (Lutz \& Neiva, 1912) (Diptera: Psychodidae: Phlebotominae) populations from endemic areas of American visceral leishmaniasis in northeastern Brazil. J Trop Med. 2012;2012:858657.

9. Jiménez M, González E, Iriso A, Marco E, Alegret A, Fúster F, et al. Detection of Leishmania infantum and identification of blood meals in Phlebotomus perniciosus from a focus of human leishmaniasis in Madrid. Spain. Parasitol Res. 2013;112:2453-9.

10. Marassá AM, Galati EAB, Bergamaschi DP, Consales CA. Blood feeding patterns of Nyssomyia intermedia and Nyssomyia neivai (Diptera, Psychodidae) in a cutaneous leishmaniasis endemic area of the Ribeira Valley, State of São Paulo Brazil. Ver Soc Bras Med Trop. 2013;46:547-54.

11. Baum M, de Castro EA, Pinto MC, Goulart TM, Baura W, Klisiowicz Ddo R, et al. Molecular detection of the blood meal source of sand flies (Diptera: Psychodidae) in a transmission area of American cutaneous leishmaniasis. Acta Trop. 2015;143:8-12.

12. Sales KG, Costa PL, de Morais RC, Otranto D, Brandão-Filho SP, Cavalcanti Mde $P$, et al. Identification of phlebotomine sand fly blood meals by realtime PCR. Parasit Vectors. 2015;8:230.

13. Rodrigues ACM, Magalhães RD, Romcy KAM, Freitas JLS, Melo ACFL, Rodon FCM, et al. A new whole mitochondrial genome APCR (WMGqPCR) with SYBR Green ${ }^{\circledR}$ to identify phlebotomine sand fly blood meals. Vet Parasitol. 2017;38:17-23.

14. Bennai K, Tahir D, Lafri I, Bendjaballah-Laliam A, Bitam I, Parola P. Molecular detection of Leishmania infantum DNA and host blood meal identification in Phlebotomus in a hypoendemic focus of human leishmaniasis in northern Algeria. PLoS Negl Trop Dis. 2018;12:e0006513.

15. Sant'Anna MR, Jones NG, Hindley JA, Mendes-Sousa AF, Dillon RJ, Cavalcante RR, et al. Blood meal identification and parasite detection in laboratory-fed and field-captured Lutzomyia longipalpis by PCR using FTA databasing paper. Acta Trop. 2008;107:230-7.

16. Kent RJ. Molecular methods for arthropod blood meal identification and applications to ecological and vector-borne disease studies. Mol Ecol Resour. 2009;9:4-18.

17. Applied Biosystems. TaqMan ${ }^{\circledR}$ multiplex PCR optimization for optimization of multiplex PCR using 7500/7500 Fast, ViiA ${ }^{\mathrm{TM}} 7$, and QuantStudio ${ }^{\mathrm{TM}}$ real time PCR systems. Publication part number MAN0010189. Thermo Fisher Scientific. 2014. https://assets.thermofisher.com/TFS-Assets/LSG/ manuals/taqman_optimization_man.pdf. Accessed 2 Nov 2019.

18. Francino O, Altet L, Sánchez-Robert E, Rodriguez A, Solano-Gallego L, Alberola J, et al. Advantages of real-time PCR assay for diagnosis and monitoring of canine leishmaniosis. Vet Parasitol. 2006;137:214-21.

19. Dantas-Torres F, Sales KGS, Silva LG, Otranto D, Figueredo LA. LeishmaniaFAST15: a rapid, sensitive and low-cost real-time PCR assay for the detection of Leishmania infantum and Leishmania braziliensis kinetoplast DNA in canine blood samples. Mol Cell Probes. 2017;31:65-9.

20. Caraguel CG, Stryhn H, Gagné N, Dohoo IR, Hammell KL. Selection of a cutoff value for real-time polymerase chain reaction results to fit a diagnostic purpose: analytical and epidemiologic approaches. J Vet Diagn Invest. 2011;23:2-15.

21. Bustin SA, Benes V, Garson JA, Hellemans J, Huggett J, Kubista M, et al. The MIQE guidelines: minimum information for publication of quantitative real-time PCR experiments. Clin Chem. 2009:55:611-22.

22. Sales KGS, de Oliveira Miranda DE, Costa PL, da Silva FJ, Figueredo LA, Brandão-Filho SP, et al. Home sweet home: sand flies find a refuge in remote indigenous villages in north-eastern Brazil, where leishmaniasis is endemic. Parasit Vectors. 2019;12:118.

23. Johnson G, Nour AA, Nolan T, Huggett J, Bustin S. Minimum information necessary for quantitative real-time PCR experiments. Methods Mol Bio. 2014;1160:5-17.

24. Pan P, Jin W, Li X, Chen Y, Jiang J, Wan H, et al. Optimization of multiplex quantitative polymerase chain reaction based on response surface methodology and an artificial neural network-genetic algorithm approach. PLoS ONE. 2018;13:e0200962.

25. Jaouadi K, Bettaieb J, Bennour A, Salem S, Ghawar W, Rjeibi MR, et al. Blood meal analysis of phlebotomine sandflies (Diptera: Psychodidae: Phlebotominae) for Leishmania spp. identification and vertebrate blood origin, central Tunisia, 2015-2016. Am J Trop Med Hyg. 2018;98:146-9.

26. Daba S, Daba A, Shehata MG, El Sawaf BM. A simple micro-assay method for estimating blood meal size of the sand fly, Phlebotomus langeroni (Diptera: Psychodidae). J Egypt Soc Parasitol. 2004;34:173-82.

27. Haouas N, Pesson B, Boudabous R, Dedet JP, Babba H, Ravel C. Development of a molecular tool for the identification of Leishmania reservoir 
host by blood meal analysis in the vectors. Am J Trop Med Hyg. 2007;77:1054-9.

28. Wittwer CT, Herrmann MG, Gundry CN, Elenitoba-Johnson KS. Real-time multiplex PCR assays. Methods. 2001;25:430-42.

29. Molenkamp R, van der Ham A, Schinkel J, Beld M. Simultaneous detection of five different DNA targets by real-time Taqman PCR using the Roche LightCycler480: application in viral molecular diagnostics. J Virol Methods. 2007; 14:205-11.

30. Pelletier C, Salar P, Ph Gillet J, Cloquemin G, Very P, Foissac X, et al. Triplex real-time PCR assay for sensitive and simultaneous detection of grapevine phytoplasmas of the 16SrV and 16SrXII-A groups with an endogenous analytical control. Vitis. 2009;48:87-95.

31. Rogers WO, Wirth DF. Kinetoplast DNA minicircles: regions of extensive sequence divergence. Proc Natl Acad Sci USA. 1987;84:565-9.

32. Bezerra-Vasconcelos DR, Melo LM, Albuquerque ÉS, Luciano MC, Bevilaqua CM. Real-time PCR to assess the Leishmania load in Lutzomyia longipalpis sand flies: screening of target genes and assessment of quantitative methods. Exp Parasitol. 2011;129:234-9.

33. Cunha RC, Andreotti R, Cominetti MC, Silva EA. Detection of Leishmania infantum in Lutzomyia longipalpis captured in Campo Grande, MS. Rev Bras Parasito Vet. 2014;23:269-73.
34. Rangel EF, Lainson R. Proven and putative vectors of American cutaneous leishmaniasis in Brazil: aspects of their biology and vectorial competence. Mem Inst Oswaldo Cruz. 2009;104:937-54.

35. Brazil RP, Rodrigues AAF, Andrade Filho JD. Sand fly vectors of Leishmania in the Americas-a mini review. Entomol Ornithol Herpetol. 2015;4:144.

36. Mendonça MG, de Brito ME, Rodrigues EH, Bandeira V, Jardim ML, Abath FG. Persistence of Leishmania parasites in scars after clinical cure of American cutaneous leishmaniasis: is there a sterile cure? J Infect Dis. 2004:189:1018-23.

37. Vergel C, Palacios R, Cadena H, Posso CJ, Valderrama L, Perez M, et al. Evidence for Leishmania (Viannia) parasites in the skin and blood of patients before and after treatment. J Infect Dis. 2006;194:503-11.

38. Lima BS, Dantas-Torres F, de Carvalho MR, Marinho-Junior JF, de Almeida EL, Brito ME, et al. Small mammals as hosts of Leishmania spp. in a highly endemic area for zoonotic leishmaniasis in north-eastern Brazil. Trans R Soc Trop Med Hyg. 2013;107:592-7.

\section{Publisher's Note}

Springer Nature remains neutral with regard to jurisdictional claims in published maps and institutional affiliations.
Ready to submit your research? Choose BMC and benefit from:

- fast, convenient online submission

- thorough peer review by experienced researchers in your field

- rapid publication on acceptance

- support for research data, including large and complex data types

- gold Open Access which fosters wider collaboration and increased citations

- maximum visibility for your research: over $100 \mathrm{M}$ website views per year

At BMC, research is always in progress.

Learn more biomedcentral.com/submissions 